\title{
Pulmonary adenocarcinoma: review of 106 cases and proposed new classification
}

\author{
C W EDWARDS
}

From the Department of Histopathology, East Birmingham Hospital

SUMMARY The gross and microscopic appearances of 106 resected pulmonary adenocarcinomas were reviewed and correlated with postoperative survival. Instead of using an established classification based on histological pattern, the tumours were categorised by cellular morphology and site as either parenchymal adenocarcinoma (67\%), bronchial adenocarcinoma (13\%), or adenocarcinoma of uncertain origin (20\%). Despite their pleomorphic appearance parenchymal adenocarcinomas should be regarded as a single entity, derived from multipotential cells of the distal airway; bronchial adenocarcinomas were generally, but not invariably, associated with short postoperative survival; those tumours that could not be reclassified on histological grounds were large adenocarcinomas consisting mainly of mucus cells. Tumours of this type carry a poor prognosis.

Current classifications of adenocarcinoma of the lung ${ }^{12}$ are unsatisfactory because little distinction is made between tumours of the larger central bronchi and those of the parenchyma, and also because the emphasis is on pattern rather than cell type. The World Health Organisation ${ }^{2}$ divides adenocarcinomas into acinar and papillary adenocarcinoma, bronchioloalveolar carcinoma, and solid carcinoma with mucus formation, while the Working Party for Therapy of Lung Cancer ${ }^{3}$ categorises them as well, moderately, or poorly differentiated, or bronchopapillary.

It is now becoming apparent that parenchymal adenocarcinomas may contain cells differentiating towards type II pneumocytes, mucus cells, Clara cells, or ciliated bronchiolar lining cells ${ }^{4-14}$ and in some instances neuroendocrine cells. ${ }^{1516}$ Tumours of the larger bronchi, on the other hand, seem to be derived from either the surface epithelium or bronchial glands. ${ }^{1718}$ The five year survival for pulmonary adenocarcinoma quoted in published reports varies between 0 and $36 \%,{ }^{819}$ and little is known about the natural history of parenchymal as opposed to bronchial tumours.

In this investigation 106 resected adenocarcinomas of the lung were reviewed to correlate light micro-

Accepted for publication 3 September 1986 scopic appearance, site of origin, and survival, with the aim of formulating a new classification based on histogenesis.

\section{Material and methods}

The pathology and available clinical details of 106 surgically resected pulmonary adenocarcinomas submitted to the histopathology department of this hospital between 1971 and 1980 were reviewed. Partially resected tumours and bronchioloalveolar carcinomas were excluded. The following definitions were used: Adenocarcinoma A malignant epithelial tumour with tubular, acinar, or papillary pattern with or without mucus secretion, or a tumour fulfilling the WHO criteria for solid carcinoma with mucus formation. ${ }^{2}$ Circumscribed tumours with cells lining intact alveolar walls at the periphery were included.

Bronchioloalveolar carcinoma A tumour diffusely affecting one or more bronchopulmonary segments, a lobe, or a lung and showing a predominantly "lepidic" pattern, with cells lining intact alveolar walls.

In each case a description of the gross specimen was available, together with between two and eight sections of the tumour, sections of unaffected lung, and where applicable, sections of lymph nodes and the bronchial resection line. The original records of many of the patients had been destroyed, but the date of death or last follow up was obtained from the West 
Midlands Regional Cancer Registry in all but four cases.

Sections were stained with haematoxylin and eosin and periodic acid Schiff with and without diastase, and in some instances with alcian blue, Best's mucicarmine, or Grimelius's stain. Because the material had been in paraffin blocks for up to 15 years and fixation had not been adequately controlled, it was thought that the results of more elaborate histochemical investigation would be unreliable.

The tumours were divided into three groups. The first (parenchymal adenocarcinomas) consisted of those tumours with no apparent bronchial origin, situated at or near the periphery of the lung. The second group (bronchial adenocarcinomas) included tumours arising near the hilum from a named bronchus. Tumours that could not be classified as bronchial or parenchymal in origin because of their site or size were placed in the third group.

Statistical analysis was carried out using Student's $t$ test or the $\chi^{2}$ test, whichever was appropriate.

\section{Results}

\section{GROUP I: PARENCHYMAL ADENOCARCINOMAS}

Most (71 cases; $67 \%$ ) of the tumours fell into this category. The age at presentation ranged from 31 to 74 years, with a mean of 59.45 years. There were 54 men and 17 women, giving a male:female ratio of about 3:1. The ages of the male and female patients did not differ greatly. A lobectomy had been carried out in 44 cases, a pneumonectomy in three, and a wedge or segmental resection in 21 . In addition to a segmental resection, overlying ribs had been removed because of intercostal spread in a further three.

In 57 cases $(80 \%)$ the tumour was in an upper lobe ( 22 on the left and 33 on the right). The side was not stipulated in two. Of the remainder, four were in the left lower lobe, five in the right lower lobe, and two in the right middle lobe. In three the site was not stated. Subpleural tumours tended to be ovoid or hemispherical with indrawing of the pulmonary surface, whereas those situated more deeply were roughly spherical. Their major diameter ranged from 0.7 to $9 \mathrm{~cm}$, three being less than $2 \mathrm{~cm}$, and nine more than $5 \mathrm{~cm}$ across.

\section{Histology}

Two or more of the subtypes of adenocarcinoma, as defined and illustrated by the World Health Organisation, ${ }^{2}$ were often present in the same tumour, and sometimes there were areas identical in appearance with other varieties of lung cancer. It therefore seemed appropriate to base a classification on cellular morphology rather than overall pattern.

The three most common cell types were designated

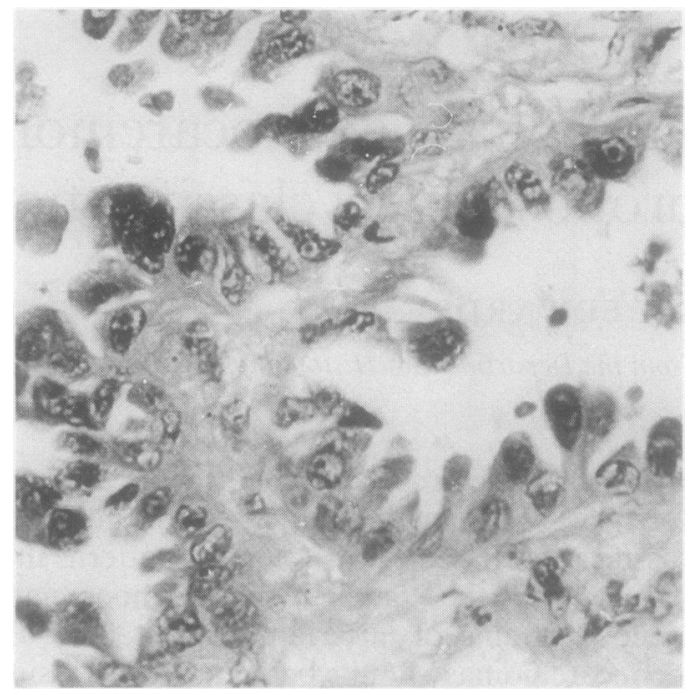

Fig 1 Parenchymal adenocarcinoma: tongue shaped cells. (Haematoxylin and eosin.) $\times 250$.

"tongue shaped," "cylindrical," and "mucous". It must be emphasised that the distinction between these $œ$ three types of cell was by no means clear cut, inteя응 mediate forms being present in most of the sections. examined. Tongue shaped cells (fig 1) were up to $40 \mu \mathrm{m}$ high and cuboid, columnar, or roughly triangular in outline. Apices were dome shaped or took the form of cytoplasmic processes extending into the lumen. The cytoplasm was eosinophilic or basophilic, and occasionally contained periodic acid Schiff positive, diastase resistant material. In five cases there were degenerate cells with round, amorphous, brightly eosinophilic inclusions, either in the cytoplasm or lying free nearby (fig 2a). Nuclei were rounded, irregular, or sometimes oval, with an open or dense chromatin pattern. They generally lay in the basal or central parts of the cytoplasm, but were also commonly found in the apical protrusions. Mitoses were plentiful. At the periphery of 16 tumours these cells tended to line alveolar walls (fig $2 b$ ), but elsewhere they formed ragged, cleft like, or rounded acini (fig 2c), or were arranged in a papillary pattern.

Cylindrical cells (fig 3) were up to $20 \mu \mathrm{m}$ high and cuboidal or columnar, with an eosinophilic faintly granular cytoplasm that often contained periodic acid Schiff positive, diastase resistant material. Their apices were flattened, sometimes with rudimentary or $\stackrel{0}{\varnothing}$ distorted cilia, but in general a row of such cells $\stackrel{\Phi}{\mathscr{D}}$ presented a smooth unbroken surface. Nuclei were basal or central, with an open chromatin pattern and a prominent eosinophilic nucleolus. Moderate numbers of mitoses were present. These cells lined intact 

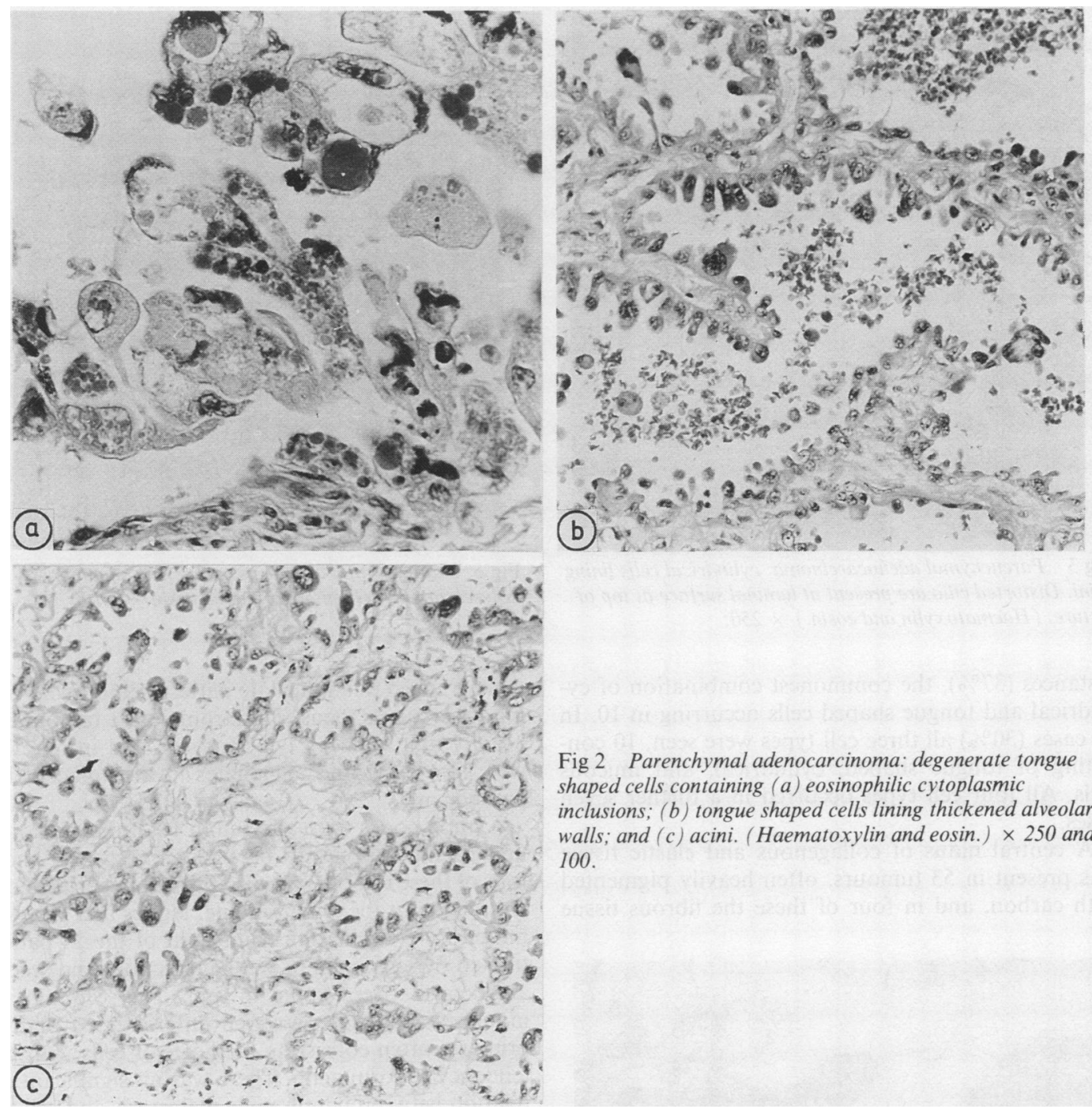

Fig 2 Parenchymal adenocarcinoma: degenerate tongue shaped cells containing $(a)$ eosinophilic cytoplasmic inclusions; (b) tongue shaped cells lining thickened alveolar walls; and (c) acini. (Haematoxylin and eosin.) $\times 250$ and 100.

alveolar walls in only four tumours. Elsewhere they formed rounded or smoothly irregular acini. A papillary arrangement was commonly seen.

Mucous cells (fig 4) were cuboidal, or low columnar, and up to $40 \mu \mathrm{m}$ high. Nuclei were round or slightly irregular, with an open chromatin pattern and often a single eosinophilic nucleolus. The cytoplasm was pale and eosinophilic, granular, or vacuolated, the vacuoles being empty or containing material giving positive histochemical reactions for mucin. These cells lined alveoli in only one case; in the others they formed acini lined by single or multiple layers of cells or were arranged in sheets and cords, or smaller aggregates. There were no examples of solid carcinoma with mucus formation.
Foci of squamous differentiation, occasionally with keratinisation of individual cells or pearl formation, were present in 18 tumours (fig 5), and in three there were areas of small cell (oat cell) carcinoma (figs 6a and b). Giant and spindle cell carcinoma was represented in nine tumours (fig 7a), and in a further eight undifferentiated polygonal cells were arranged in solid nodular or trabecular patterns, often with a palisade at the edge - an appearance resembling that of carcinoid tumour (fig $7 \mathrm{~b}$ ).

Tongue shaped cells were present in 48 tumours, cylindrical cells in 31 , and mucus cells in 22 . Only 17 tumours (24\%) were of one cell type, seven consisting of tongue shaped cells, seven of cylindrical cells, and three of mucus cells. Two cell types were present in 26 


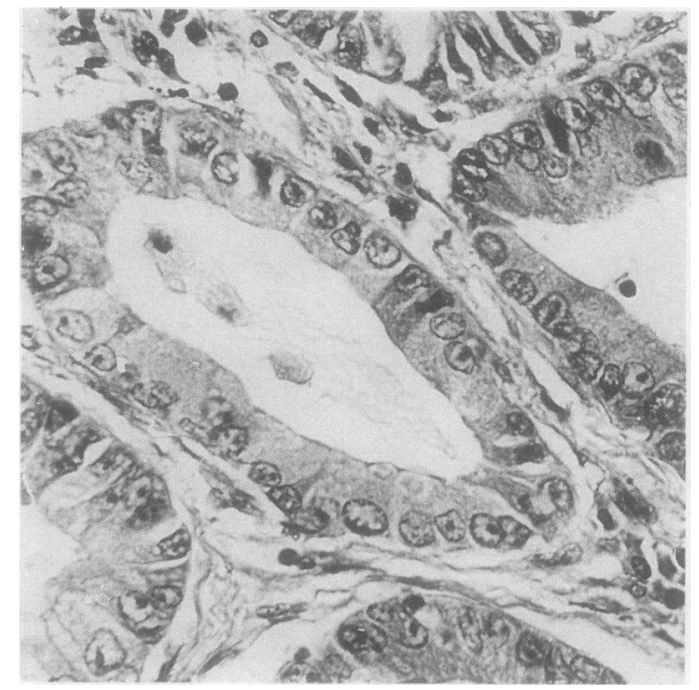

Fig 3 Parenchymal adenocarcinoma: cylindrical cells lining acini. Distorted cilia are present at luminal surface at top of picture. (Haematoxylin and eosin.) $\times 250$.

instances $(37 \%)$, the commonest combination of cylindrical and tongue shaped cells occurring in 10. In 21 cases $(30 \%)$ all three cell types were seen, 10 consisting of tongue shaped, cylindrical, and mucous cells. All four cell types occurred in a further seven cases.

A central nidus of collagenous and elastic tissue was present in 53 tumours, often heavily pigmented with carbon, and in four of these the fibrous tissue

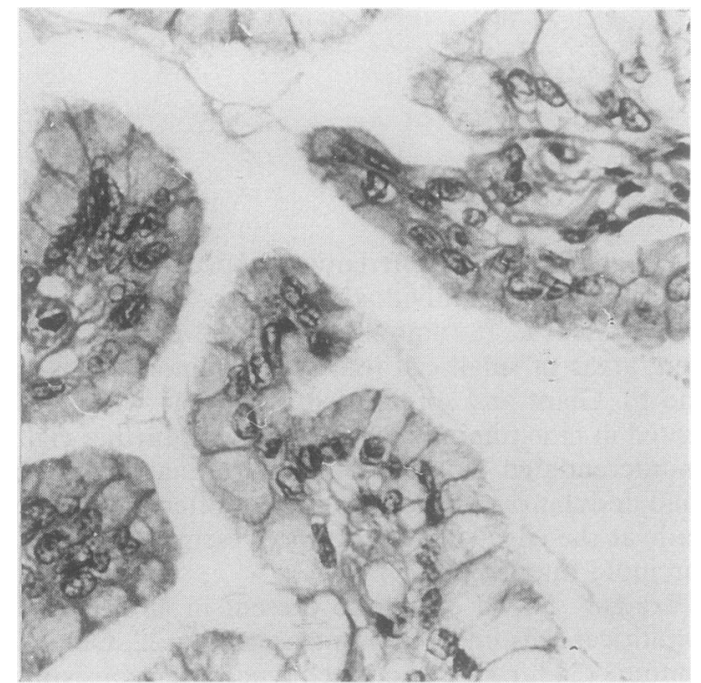

Fig 4 Parenchymal adenocarcinoma: mucus cells lining thickened alveolar walls. (Haematoxylin and eosin.) $\times 250$.

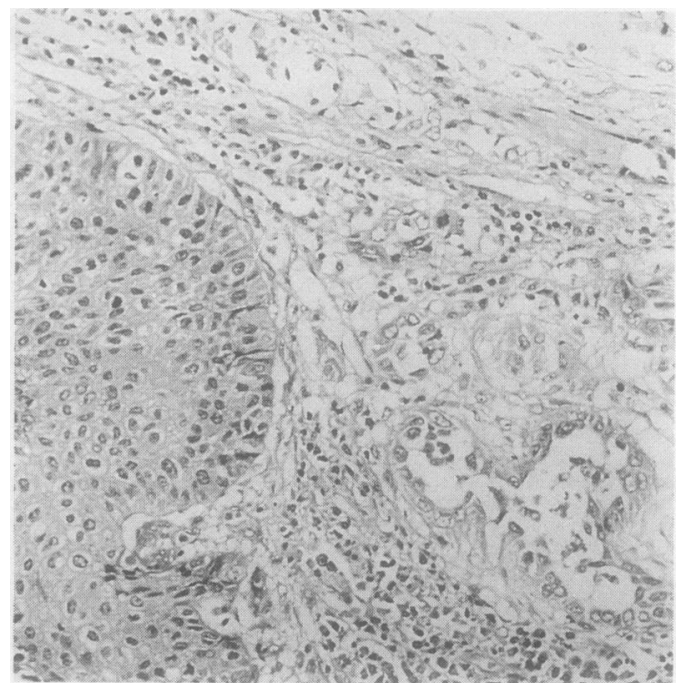

Fig 5 Parenchymal adenocarcinoma with squamous differentiation. (Haematoxylin and eosin.) $\times 100$.

was arranged in a lamellate pattern reminiscent of an old tuberculous focus. The stroma of 11 tumours wa尺 heavily infiltrated by lymphocytes, and in one there were also lymphoid aggregates in the adjacent lung parenchyma.

Lymph nodes were affected in 18 of the 47 patients undergoing lobectomy or pneumonectomy, and in four of these tumour was also present in peribronchial lymphatics at the resection line. Nodes had been submitted for examination from eight of the 24 patients treated by segmental or wedge resection, and secondary deposits were found in four. The secondary tumour was generally less well differentiated than the primary, often consisting of sheets of cells with little tendency to form acini. There was no significant correlation between lymph node metastasis and cell type or tumour size, although there was a tendency for lymph nodes to be more commonly affected when the primary tumour was over $5 \mathrm{~cm}$ in diameter.

\section{Survival}

Fig 8 shows the survival in the group as a whole for the first five years after surgery. Twelve patients survived for periods of between five and 10 years, and nine remained alive five to 11 years after operation. Ten died in the immediate postoperative period.

Fig 9 shows the five year survival of the patients treated by pneumonectomy or lobectomy, with and without lymph node disease. In those with lymph node metastasis the mean survival was 12.19 months, in contrast to those without, where the mean survival was 52.52 months, the difference being significant ( $p$

\section{$\stackrel{-1}{\circ}$} $\dot{0}$ 3. 올 윽 ه 


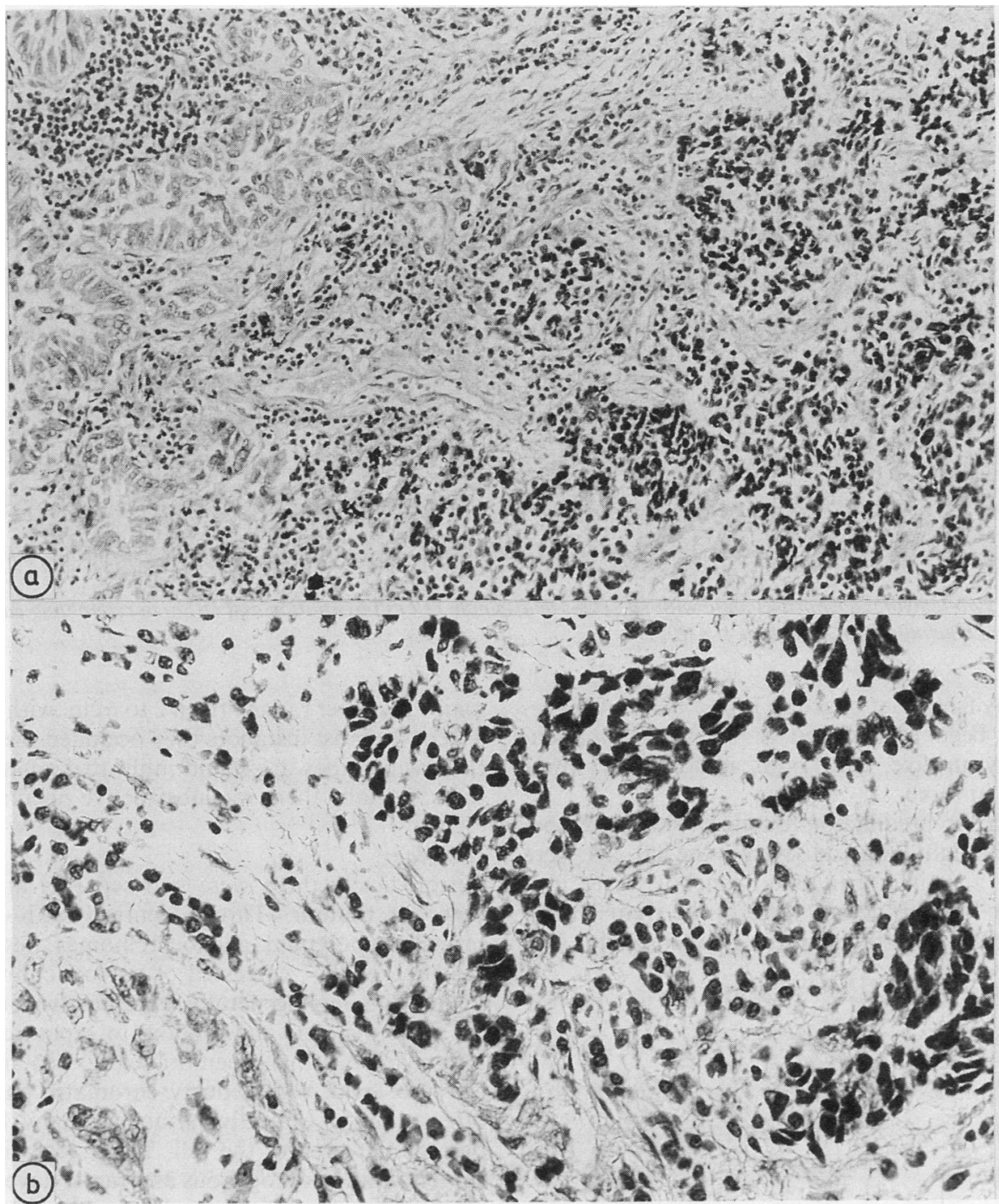

Figs $6 \mathrm{a}$ and $\mathrm{b}$ Parenchymal adenocarcinoma with small cell differentiation. (Haematoxylin and eosin.) $\times 100$ and 250 .

$<0.01$ ). Overall, mean survival after lobectomy or pneumonectomy was 37.51 months.

After segmental or wedge resection mean survival was 37.77 months, with a range of less than one to 122 months. The four patients with confirmed lymph node metastases survived six, 38, 63 and 96 months, respectively. Two patients with no histological evidence of lymph node disease lived for 10 months, and one for 13 months. A further patient was still alive 10 years after surgery. All three patients undergoing rib resection died within one month of operation.
There was no correlation between survival and age, sex, tumour size or cell type. Two patients with tumours containing foci of giant cell carcinoma survived for five years, and one with areas of small cell carcinoma for eight.

\section{GROUP II: BRONCHIAL ADENOCARCINOMA}

In 14 patients $(13 \%)$ the tumour arose from a major bronchus near the hilum. The ages of the patients ranged from 43 to 74 years, with a mean of 59.36 years. All were male, the sex incidence differing 


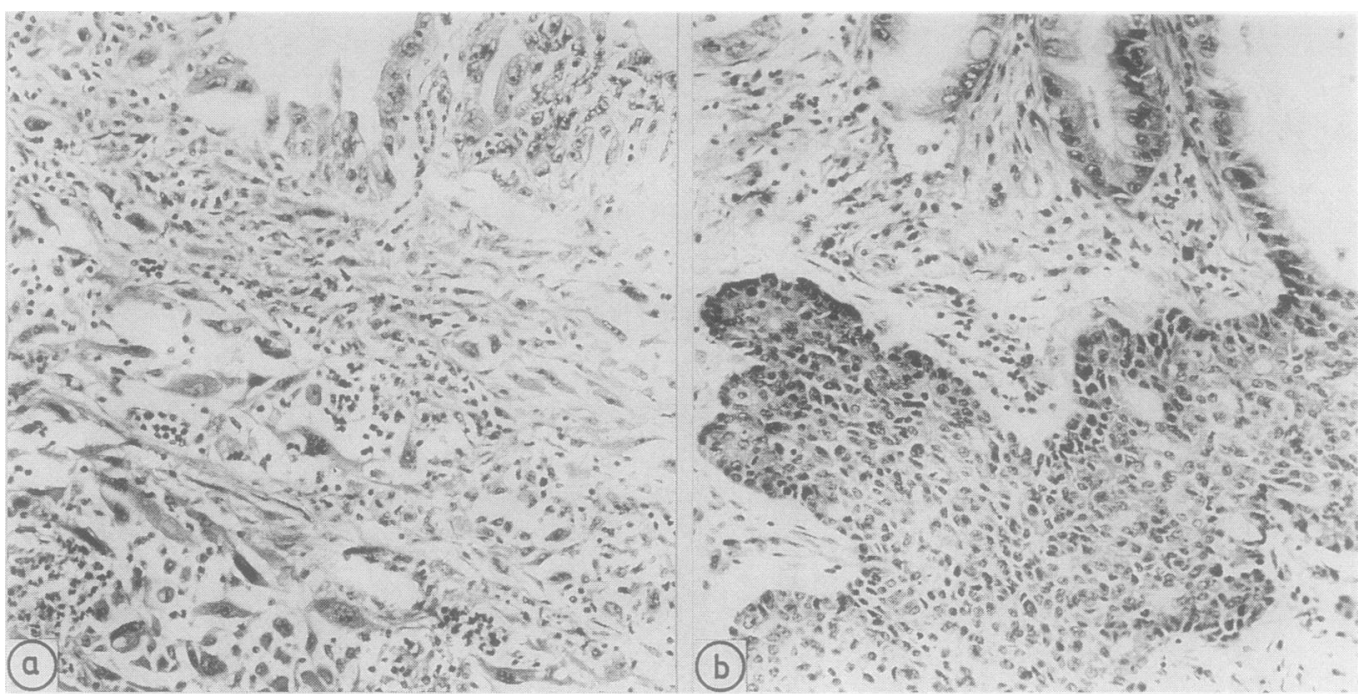

Fig 7 Parenchymal adenocarcinoma with (a) giant and spindle cell differentiation and (b) area resembling carcinoid tumour. (Haematoxylin and eosin.) $\times 100$.

significantly from that of group I ( $p<0.05)$. A lobectomy had been carried out in six cases, a pneumonectomy in five, and right middle and lower lobectomy in three.

There was no prediliction for site or side: seven occurred in the right lung and seven in the left; five were situated in a main upper lobe bronchus, three in a main lower lobe bronchus, three in the right middle lobe bronchus, and three in the main bronchi. The

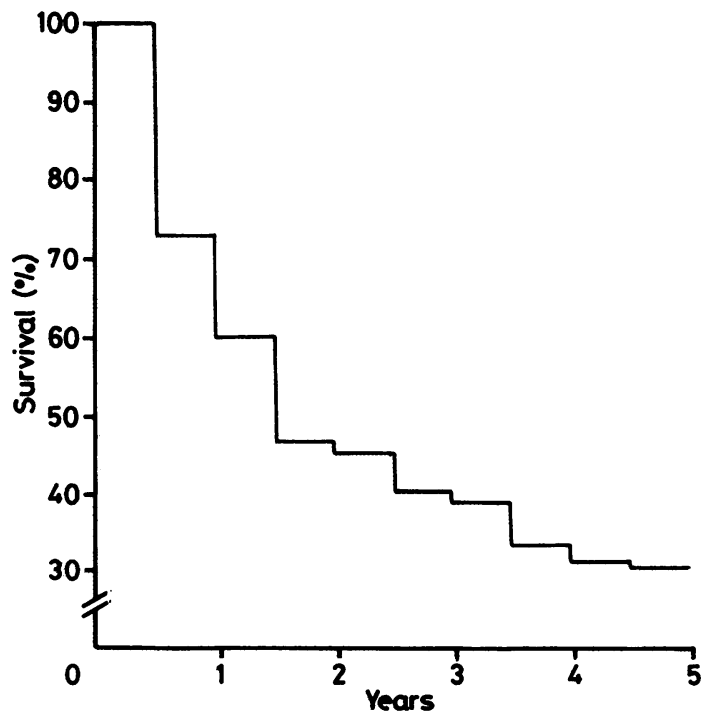

Fig 8 Parenchymal adenocarcinoma: overall five year survival. major diameter ranged from 2 to $6 \mathrm{~cm}$, with a mean of $4.2 \mathrm{~cm}$. In most instances they occluded the bronchus from which they arose and infiltrated adjacent struce tures. Distally there was obstructive pneumonitis.

\section{Histology}

Histologically there were two separate and distinct types of tumour. Three, identical with the endobronchial polypoid adenocarcinomas described by Kodama et al, ${ }^{18}$ consisted of narrow columnar cells up to $30 \mu \mathrm{m}$ high, generally separated from each other by a narrow cleft and tending to separate from the underlying basement membrane (figs $10 \mathrm{a}$ and $\mathrm{b}$ ). $\mathrm{Nu}$ clei were oval, with a dusty chromatin pattern, and often situated centrally, although many lay at the base or the apex of the cell. The cytoplasm was eosinophilic and homogenous and rarely gave a positive reaction for mucin. At the luminal surface the cells covered papillary fibrous tissue cores heavily infiltrated by lymphocytes (fig 10a). In the deeper parts of the tumour they lined irregular acini (fig 10b). Mitoses were common. Lymph nodes were affected in two cases, and in one there were also deposits of tumour in peribronchial lymphatics.

The 11 other tumours fulfilled the WHO criteria for acinar adenocarcinoma, ${ }^{2}$ and were therefore designated bronchial acinar adenocarcinoma. They consisted of mucus cells identical with those described in the previous section, together with polygonal or cuboidal, rather granular, deeply eosinophilic or amphophilic cells (fig 11). The nuclei of these latter elements were round or irregular, with an open chromatin pattern. Both types of cell lined acini or formed 


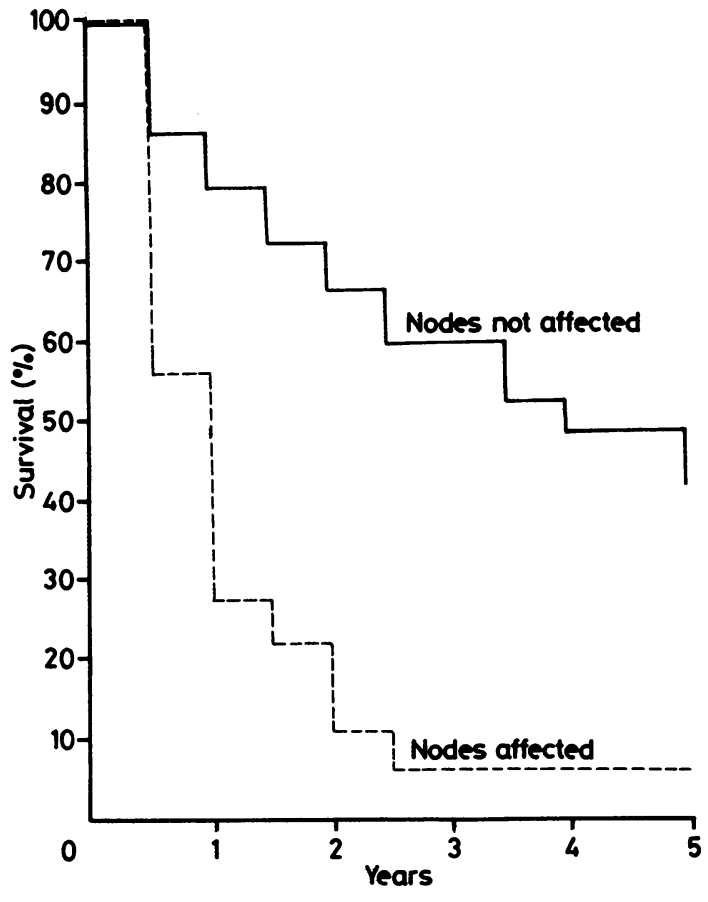

Fig 9 Parenchymal adenocarcinoma: five year survival of patients treated by lobectomy and pneumonectomy.

clusters and larger masses: intermediate variants were common. There was often extensive necrosis, and mitoses were abundant. Two cases were characterised by spread beneath the intact bronchial epithelium, breaking through in some areas to form blunt papillary processes: in both there was cellular proliferation and irregularity of the ducts of adjacent bronchial glands. Lymph nodes were affected in six cases, associated with metastasis in the bronchial resection line in three. In one case there was tumour at the resection line, but none in hilar lymph nodes.

The overall incidence of lymph node metastases in group II was $57 \%$, as opposed to $40 \%$ in group I. The difference was not significant.

\section{Survival}

Fig 12 shows the survival of the patients in group II. One patient with an endobronchial papillary adenocarcinoma was still alive seven years after operation, and one patient with bronchial acinar carcinoma survived 13 years and is still alive at the time of writing. In both cases hilar lymph nodes were affected. A further patient with acinar adenocarcinoma died after eight years; in this case lymph nodes were not affected. The four patients with tumour at the bronchial resection line survived for between two and five months.

The number of patients in this group was too small for statistical analysis or comparison with the cases of parenchymal adenocarcinoma.

\section{GROUP III: ADENOCARCINOMAS OF UNCERTAIN ORIGIN}

The site of origin, whether bronchial or parenchymal, was uncertain in 21 cases $(20 \%)$. There were two female and 19 male patients, their ages ranging from 47 to 72 years (mean 59.85 years). Six pneumonectomies, 14 lobectomies, and a right middle and lower lobec-

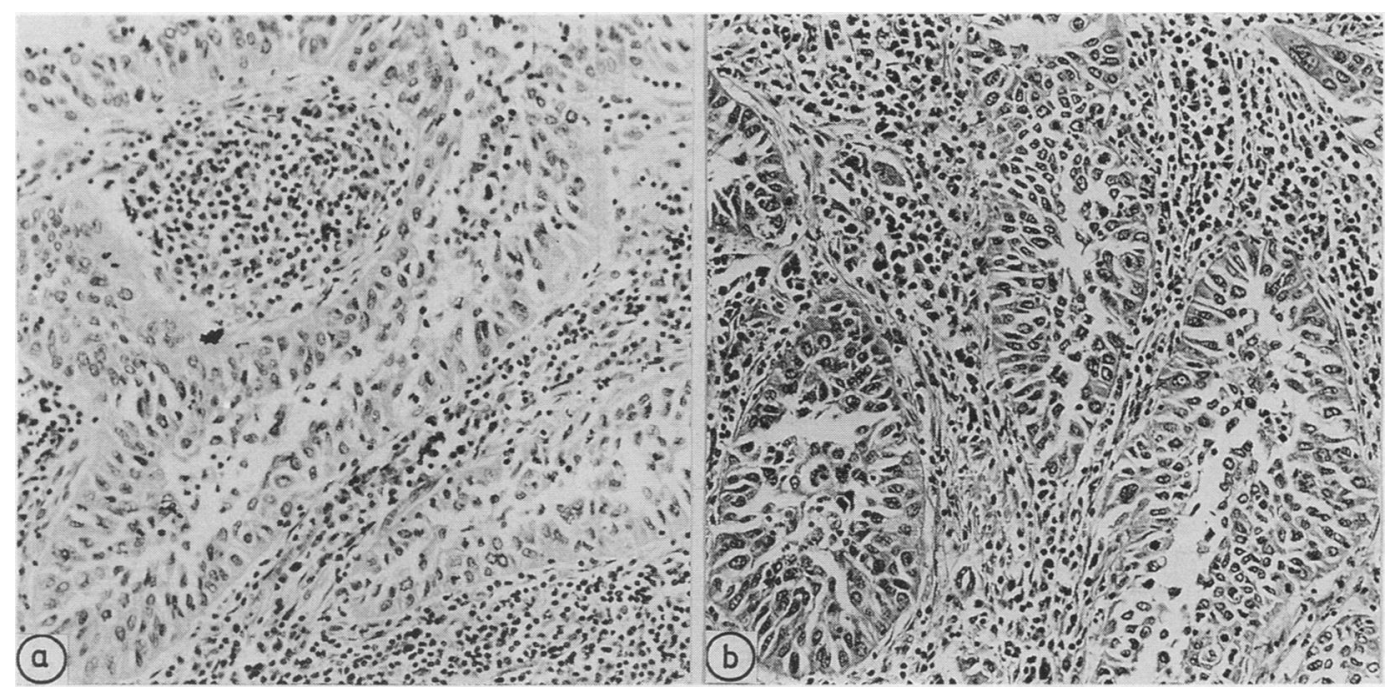

Fig 10 Endobronchial polypoid adenocarcinoma with (a) papillary pattern at surface; and (b) acinar pattern in deeper parts of tumour. (Haematoxylin and eosin.) $\times 100$. 


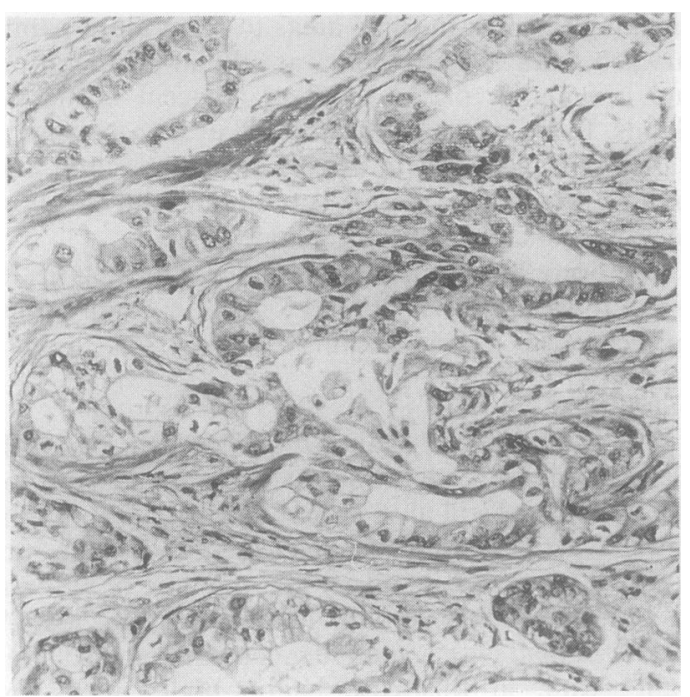

Fig 11 Bronchial acinar adenocarcinoma: acini are lined by mucus cells and those with faintly granular eosinophilic cytoplasm. (Haematoxylin and eosin.) $\times 100$.

tomy had been carried out in this group.

One tumour was $2 \mathrm{~cm}$ in diameter, one $3 \mathrm{~cm}$, and two $4 \mathrm{~cm}$. The remainder were between 5 and $18 \mathrm{~cm}$ across (mean $6.71 \mathrm{~cm}$ ). In two cases there were two tumours, 5 and $6 \mathrm{~cm}$, and 8 and $10 \mathrm{~cm}$ in diameter, respectively. Nine were situated wholly or for the most part in an upper lobe, nine in a lower lobe, and two in the right middle lobe. In one instance the tumour had replaced the entire left lung.

\section{Histology}

By applying the criteria outlined in the two previous sections, eight tumours were reclassified as parenchy-

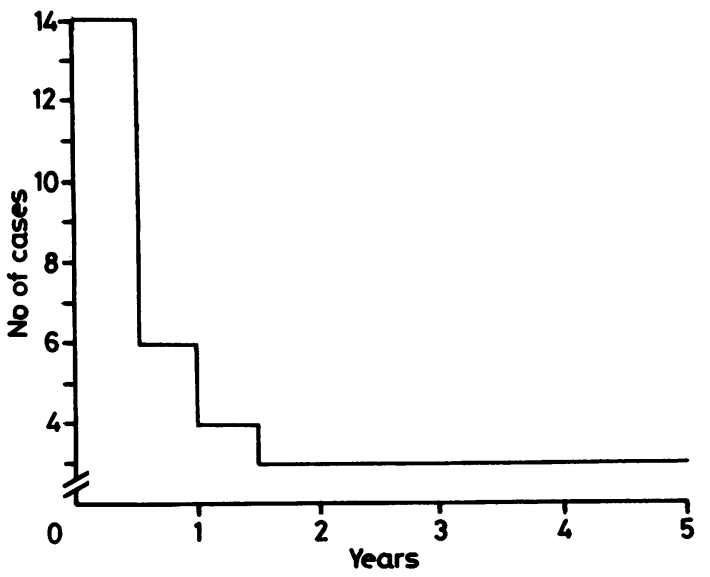

Fig 12 Bronchial adenocarcinoma: five year survival. mal adenocarcinomas. All of these contained tongue shaped cells-five also contained cylindrical cells, and mucus cells were present in two. Two other tumours, each $4 \mathrm{~cm}$ in diameter, comprised mucus and eosinophilic polygonal cells, and showed extensive spread under the epithelium of a peripheral bronchus, with proliferation of the ducts of adjacent glands. Appearances were identical with those of bronchial acinar adenocarcinoma, although a bronchial origin was by no means certain.

The remainder consisted almost entirely of mucus cells arranged in acini or sheets, with widespread necrosis and infiltration of both the parenchyma and airways. In three there were foci of squamous differentiation, and in one there was an area of small cell carcinoma. All were $6 \mathrm{~cm}$ or more in diameter, and among them were the two cases with two tumours.

Lymph nodes were affected in 11 cases, and there was tumour in lymphatics at the bronchial resection line in two.

\section{Survival}

The survival of two patients from this group was unknown at the time of writing. Fig 13 shows the survival of the other 19. Excluding two patients dying in the immediate postoperative period, the mean sur -7 vival for this group was 11.8 months (range 2 to 54 months). Only two patients lived more than 18

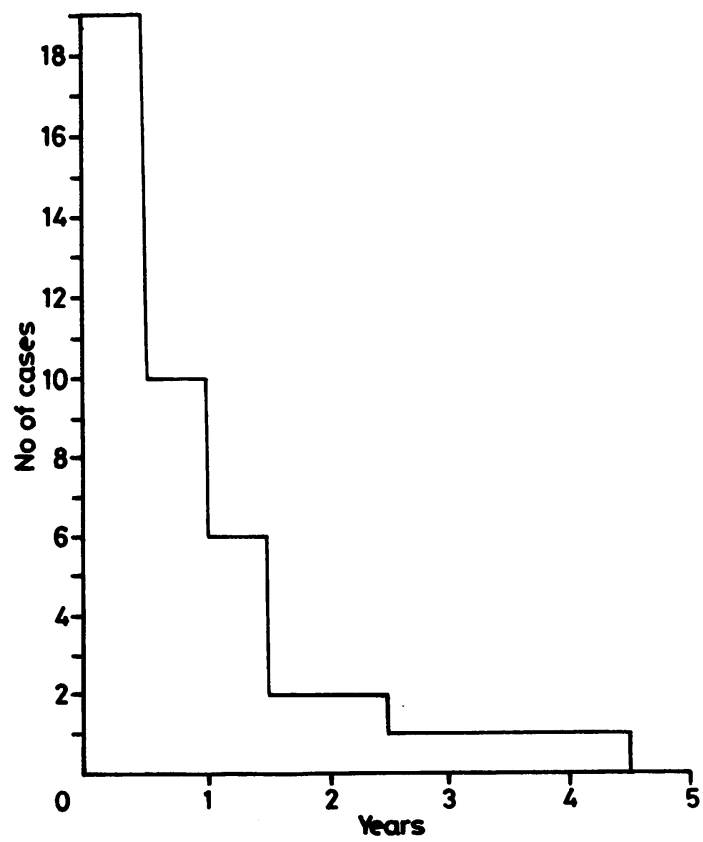

Fig 13 Adenocarcinoma of uncertain origin: five year survival. 
months after surgery. In one the tumour was a parenchymal adenocarcinoma, and in the other the tumour was of mucus cell type. Neither showed lymph node metastasis.

\section{Discussion}

The WHO classification of pulmonary adenocarcinoma ${ }^{2}$ is widely accepted and has been used as a basis for several studies. ${ }^{591112}$ This classification and others like it, however, do not correlate well with ultrastructural morphology. ${ }^{78}$ Peripheral adenocarcinomas contain elements characteristic of goblet cells, Clara cells, type II pneumocytes and ciliated bronchiolar lining cells.4-14 Even on light microscopy, the pattern is highly variable, sometimes with all of the WHO subtypes represented in the same tumour. ${ }^{20}$ The emphasis in this investigation, therefore, was on cell type rather than pattern.

The results show that tumours arising in the lung parenchyma contain tongue shaped, cylindrical, and mucus cells in varying proportions. Any of these cell types can line acini, papillary structures, or alveolar walls, and in the case of mucus cells may form solid areas. Previous ultrastructural investigations ${ }^{14}$ have indicated that tongue shaped cells represent Clara cell differentiation, and although the nature of the cylindrical cells is less certain, they have certain features in common with immature ciliated bronchiolar lining cells. Cuboidal cells may resemble type II pneumocytes, but without the benefit of electron microscopy and cytochemisty, their nature is uncertain. The eosinophilic cytoplasmic inclusions seen in some cases have previously been described in tumours of the lung and other organs, and seem to be unsaturated complex proteins. $^{21}$

As well as cells resembling those of the epithelium of the distal airways, there may also be squamous and giant cell change, or areas identical with carcinoid tumour or small cell carcinoma. Such apparent neuroendocrine differentiation must be interpreted with caution in the absence of histochemical and ultrastructural confirmation. Although neurosecretory granules have been shown in pulmonary adenocarcinomas, ${ }^{1516}$ poorly differentiated squamous carcinomas may be identical with small cell carcinoma on light microscopy, ${ }^{22}$ and poorly differentiated adenocarcinomas of the large bowel sometimes resemble atypical carcinoid tumour. This heterogeneity of cell type may lead to incorrect diagnoses being made on biopsy material, and consequently to inappropriate treatment. Parenchymal adenocarcinomas seem to be tumours of multipotential cells, derived from distal airways, and able to differentiate in several directions. Despite their morphological diversity they should be regarded as a single entity.

Over $13 \%$ of the tumours in the present series arose in larger central bronchi-a higher proportion than the $2.7 \%$ reported in a recent Japanese study. ${ }^{17}$ This discrepancy can be accounted for by the high prevalence of parenchymal adenocarcinoma in the Far East, ${ }^{1723}$ but no explanation can be offered for the total absence of large airway adenocarcinomas in earlier series from England ${ }^{24}$ and North America. ${ }^{25} 26$

Two variants of bronchial, as opposed to parenchymal, adenocarcinoma have been defined recently. ${ }^{17} 18$ Endobronchial polypoid adenocarcinoma, as its name suggests, presents as a polypoid mass in a large bronchus. It is composed of cells with the ultrastructural features of ciliated bronchial epithelial cells. Mucus secreting elements and cells containing Clara cell granules may also be present, suggesting that it has the ability to differentiate towards bronchial or bronchiolar surface epithelium. A histogenetic origin from bronchial basal cells has been postulated. Adenocarcinoma of bronchial gland cell type $\mathrm{P}^{17}$ consists of cells arranged in acini and tubules, some of which contain mucoid material, while others have a granular eosinophilic cytoplasm. Myoepithelium like spindle cells may also be present. Ultrastructurally, many cells show either mucus secretion or secretory granules similar to those of serous cells, and some seem to be the neoplastic equivalent of oncocytes or collecting duct cells, while others show filamentous structures characteristic of myoepitheilial cells.

Three of the tumours in group II were of endobronchial polypoid type, and on light microscopy an origin from bronchial surface epithelium seems reasonable. The histogenesis of the remaining 11 , however, is less certain. All fulfilled the published criteria for bronchial gland carcinoma, ${ }^{17}$ and it is tempting to interpret the ductal hyperplasia and irregularity as premalignant. This latter change, however, could be degenerative or a reaction to inflammation, and it is equally possible that tumours of this type originate from the surface epithelium. Metaplasia of ciliated to mucus secreting cells has been shown to be a stage in bronchial carcinogenesis, ${ }^{27}$ and bronchial squamous carcinomas often show adenodifferentiation. ${ }^{28} 29$

About one half of the tumours in group III could be reclassified as parenchymal or bronchial adenocarcinoma, but there were 11 cases which did not fit into either of the first two groups: these consisted almost entirely of mucus cells, were all over $6 \mathrm{~cm}$ in diameter, and showed widespread necrosis. The site of origin was uncertain; they could have arisen from distal or central airway epithelium, or from bronchial gland. It may be that tumours of mucus cells behave differently to other types of pulmonary adeno- 
entity, but there are insufficient data available at present. Interestingly, none of the tumours in this series fulfilled the WHO criteria for solid carcinoma with mucus formation. ${ }^{2}$ Although some contained areas with this appearance, there was always a degree of acinar differentiation.

Comparison of the present survival figures with those of previously published series is difficult because different histological criteria have been used and no distinction has been made between bronchial and parenchymal tumours. From this study it is apparent that parenchymal tumours with no hilar lymph node metastasis carry a five year survival of about $40 \%$ : when hilar nodes are affected the five year survival falls to $9 \%$. There is no evidence to suggest that the cell type of such tumours correlates with survival. Foci of small cell or giant cell change do not necessarily imply a poor prognosis. Moreover, although it has been suggested that mucus cells are associated with short survival, ${ }^{8}$ and that tumours consisting mainly of Clara (or tongue shaped) cells behave in a relatively benign fashion, ${ }^{48}$ neither of these hypotheses could be substantiated.

The prognosis of bronchial adenocarcinoma is less clear cut. The results indicate that such cases are often associated with short survival, although three patients survived for more than five years, despite lymph node metastasis in two. In two instances the tumour was of the endobronchial polypoid type, and interestingly, two of the five similar patients reported by Kodama $e t$ $a l^{18}$ were alive 42 and 33 months after surgery. Large mucus secreting adenocarcinomas of uncertain origin carry a uniformly poor prognosis.

The aetiology of adenocarcinomas of the lung is uncertain. Unfortunately, no comment can be made about environmental factors in the present series because the records of many of the patients had been destroyed. In previously published cases tobacco seems to have been a factor, ${ }^{30}$ although the high incidence of parenchymal tumours in non-smoking subjects, particularly in the Far East, ${ }^{1723}$ cannot be explained in this way. Exposure to the fumes of paraffin stoves and incense smoke has been proposed, ${ }^{23}$ but no strong causative link has been shown. The role of pre-existing lung scars remains controversial. $^{14}$

Pulmonary adenocarcinomas can resemble secondary thyroid, renal, ovarian, or gastrointestinal carcinomas, and it is accepted that a very small proportion of the tumours in this series may have been metastatic. In all cases, however, every attempt was made to exclude a primary outside the chest on clinical grounds; it can therefore safely be assumed that the overwhelming majority arose in the bronchi or lung parenchyma.

In conclusion, parenchymal and bronchial tumours differ in light microscopic appearance, histogenesis, 0 and prognosis and seem to be separate entities. The $\stackrel{0}{=}$ exact nature of large mucus cell tumours is uncertain, 으 and further investigation is needed. The following classification of pulmonary adenocarcinoma is pro- $\stackrel{0}{\rightarrow}$ posed.

\section{PARENCHYMAL ADENOCARCINOMA}

These are pleomorphic tumours consisting of cells re- $\overparen{\odot}$ sembling those lining the distal airways, including Clara cells, immature ciliated cells, mucus cells and $\vec{\circ}$ type II pneumocytes, arranged in acinar or papillary patterns, or lining alveolar walls. Mucus cells may $\vec{\omega}$ form solid masses. Areas of differentiation towards other types of lung cancer may also be present. Small 용 tumours with no lymph node disease carry a reason- $\overrightarrow{0}$ able prognosis.

\section{BRONCHIAL ADENOCARCINOMA}

(i) Endobronchial polypoid carcinoma These are tu- 을 mours of larger central bronchi, consisting of imma- $-\overrightarrow{ }$ ture ciliated cells lining papillary processes or $T$ irregular acini.

(ii) Bronchial acinar adenocarcinoma These are tumours of larger central bronchi consisting of mucus secreting and granular eosinophilic cells arranged in $\vec{\oplus}$ acini, sheets, or cords. Bronchial adenocarcinomas $\stackrel{\infty}{.}$ are often associated with short postoperative surviva but do not necessarily carry a poor prognosis.

\section{UNCLASSIFIA B LE ADENOCARCINOMA}

These are tumours, which, because of their site and size, cannot be fitted into either of the other two groups. They usually consist of mucus cells arranged in acini, sheets, or cords, often with widespread necrosis. Such tumours are generally large and carry a poor prognosis.

I am grateful to Mrs Ruth Fry for her secretarial help and also to Mrs Sue Wilson of the West Midlands Cancer Registry for providing the survival figures.

\section{References}

1 Lamb D. Histological classification of lung cancer. Thorax 1984;39:161-5.

2 World Health Organisation. International histological classification of tumours, No 1. Histological typing of lung tumours. 2nd ed. Geneva: WHO, 1981.

3 Matthews MJ. Problems in morphology and behaviour of $\omega$ broncho-pulmonary malignant disease. In: Israel L, Chahinian $<$ AP, eds. Lung cancer-natural history, prognosis and therapy. New York: Academic Press, 1976:23-63.

4 Montes M, Binette JP, Chaudhry AP, Adler RH, Guarino R. Clara cell adenocarcinoma. Light and electron microscopic $T$ studies. Am J Surg Pathol 1977;1:245-53.

5 Kimula Y. A histochemical and ultrastructural study of adenocarcinoma of the lung. Am J Surg Pathol 1978;2:253-64. 
6 Zolliker AS, Jacques J. Clara cell carcinoma of the lung. Hum Pathol 1981;12:748-50.

7 Bolen JW, Thorning D. Histogenetic classification of pulmonary carcinomas. Peripheral adenocarcinomas studied by light microscopy, histochemistry and electron microscopy. Pathol Annu 1982;17(Pt 1):77-100.

8 Herrera GA, Alexander B, DeMoraes HP. Ultrastructural subtypes of pulmonary adenocarcinoma. A correlation with patient survival. Chest 1983;84:581-6.

9 Raino P. Ultrastructure of neoplastic cells in different histologic subtypes of pulmonary adenocarcinoma. Pathol Res Pract Commun 1983;176:216-35.

10 Espinoza CG, Balis JU, Saba SR, Paciga JE, Shelley SA. Ultrastructural and immunohistochemical studies of bronchioloalveolar carcinoma. Cancer 1984;54:2182-9.

11 Horie A, Kotoo Y, Ohta M, Kurita Y. Relation of fine structure to prognosis for papillary adenocarcinoma of the lung. Hum Pathol 1984;15:870-9.

12 Ogata T, Endo K. Clara cell granules of peripheral lung cancers. Cancer 1984;54:1635-44.

13 Singh G, Katyal SL, Ordonez NG, et al. Type II pneumocytes in pulmonary tumours. Implications for histogenesis. Arch Pathol Lab Med 1984;108:44-8.

14 Edwards C, Carlile A. Scar adenocarcinoma of the lung: a light and electron microscopic study. J Clin Pathol 1986;39:423-7.

15 McDowell E, Wilson TS, Trump BF. Atypical endocrine tumours of the lung. Arch Pathol Lab Med 1981;105:20-8.

16 Eimoto T, Teshima K, Shirakusa T, Kikuchi M. Ultrastructure of well-differentiated adenocarcinomas of the lung with special reference to bronchioloalveolar carcinoma. Ultrastruct Pathol 1985;8:177-90.

17 Kodama T, Shimosato Y, Kameya T. Histology and ultrastructure of bronchogenic and bronchial gland adenocarcinomas (including adenoid cystic and mucoepidermoid carcinomas) in relation to histogenesis. In: Shimosato $\mathrm{Y}$, Melaned MR, Nettesheim P, eds. Morphogenesis of lung cancer. Vol 1. Boca Raton, Florida: CRC Press, 1982.

18 Kodama T, Watanabe S, Shimosato T, Yoneyama T, Koide T. Endobronchial polypoid adenocarcinoma of the lung. Histological and ultrastructural studies of five cases. Am J Surg Pathol 1984;8:845-54.
19 Rubinstein I, Baum GL, Bubis JJ, Kalter Y, Lieberman Y. Prognosis of patients with adenocarcinoma of the lung and mediastinal lymph node metastases undergoing pulmonary resection. Respiration 1985;47:70-2.

20 Eskenazy A. The cylindrocubic carcinomas of the lung (the socalled adenocarcinomas). A histopathological analysis of 725 cases. Morphol Embryol (Bucur) 1984;30:41-53.

21 Dekker A, Krause JR. Hyaline globules in human neoplasms. A report of three autopsy cases. Archives of Pathology 1973;95: 178-81.

22 Churg A, Johnston WH, Stulbarg M. Small cell squamous and mixed small cell squamous-small cell anaplastic carcinomas of the lung. Am J Surg Pathol 1980;4:255-63.

23 Kung ITM, So KF, Lam TH. Lung cancer in Hong Kong Chinese: mortality and histological types, 1973-82. Br J Cancer 1984;50:381-8.

24 Walter JB, Pryce D. The site of origin of lung cancer and its relation to histological type. Thorax 1955;10:117-26.

25 Lisa JR, Salvador T, Rosenblatt MB. Site of origin, histogenesis and cytostructure of bronchogenic carcinoma. Am J Clin Pathol 1965;44:375-84.

26 Bennett DE, Sasser WF, Ferguson TB. Adenocarcinoma of the lung in men. A clinicopathologic study of 100 cases. Cancer 1969;23:431-9.

27 McDowell EM, McLaughlin JS, Merenyi DK, Kieffer RF, Harris CC, Trump BF. The respiratory epithelium. V. Histogenesis of lung carcinomas in the human. $J N C I$ 1978;61:587-606.

28 Dingemans KP, Mooi WJ. Ultrastructure of squamous cell carcinoma of the lung. Pathol Annu 1984;173:249-73.

29 Carlile A, Edwards C. Poorly differentiated squamous carcinoma of the bronchus: a light and electron microscopic study. J Clin Pathol 1986;39:284-92.

30 Vincent AG, Pickren JW, Lane WW. The changing histopathology of lung cancer: a review of 1682 cases. Cancer 1977;39:1647-55.

Requests for reprints to: Dr CW Edwards, Department of Histopathology, East Birmingham Hospital, Bordesley Green East, Birmingham B9 5ST, England. 